\title{
Evaluating Biological Effects of Sirolimus-Eluting Cardiovascular Stents
}

D01. 10, $17691 / \mathrm{stm} 2017.9 .1 .06$

Recelved October 9, 2015

A.D. Kruchinina, Research Engineer;

O.D. Lyubchenko, Research Engineer; Y.P. Yastremskaya, Research Engineer; A.N. Shatrov, Office Manager

NanoMed, 1 Tsentralnaya St., Penza, 440068, Russian Federation

The aim of the investigation was to study the influence of the sirolimus-eluting cardiovascular stents on hematological and biochemical blood parameters in vitro.

Materials and Methods. Angioplasty of aorta-iliac segment of the femoral artery was performed to six rabbits with implantation of MS $2.5 \times 11 \mathrm{~mm}$ bare metal Cobalt-Chromium stents and stents of the same model developed by NanoMed (Russia) with linear-chain carbon and drug-eluting coatings ( $2 \mu \mathrm{g} / \mathrm{mm}^{2}$ of sirolimus) to other six rabbits. Animal condition was assessed visually and by hematological and biochemical blood parameters 1, 2, 4, and 7 weeks after implantation compared to the rabbits of intact and control groups.

Results. Application of the stents with linear-chain carbon and drug-eluting coatings reduces the risk of restenosis. Gradual destruction of the polymeric coating provides local dosed release of the drug substance in the area of the stented vessel wall, inhibiting thereby the neointimal hyperplasia. Implantation of sirolimus-eluting stents did not cause significant changes in biochemical and hematological blood parameters of rabbits in comparison with bare metal stents. Changes in the blood tests of the control animals compared to the intact ones are likely to be the result of surgical intervention. This fact allows us to pass over to the clinical trials of sirolimus-eluting coronary stents.

Key words: sirolimus-eluting stent; antiproliferative stent coatings; drug-eluting stents; hematology; blood biochemistry.

Methods of coronary angioplasty and stenting are being widely used to treat ischemic heart disease, angina pectoris, diseases of peripheral arteries [1].

The main problem of their application is the development of recurrent stenosis in the remote period $[1,2]$. The probability of this complication is diminished in case of using stents with drug-eluting coatings: the clinical picture of ischemic heart disease is significantly improved, the efficiency of interventions on peripheral arteries increases, the rate of angina pectoris recurrence and the need of repeated myocardial revascularization reduce $[3,5]$.

Application of polymer-coated metal stent as a scaffold for incapsulation of a pharmaceutical preparation is necessary for a targeted delivery of the active substance to reduce proliferation intensity of vessel intima cells: gradual coating resorption provides local release of the sufficient preparation quantity essential for limiting hyperplasia in response to implantation.

The polymer layer containing a pharmaceutical substance must be biodegradable, biocompatible and nonimmunogenic, it also must preserve its properties after sterilization. Copolymers of lactic and glycolic acids meet these requirements to the full extent and are commonly used in manufacturing various medical products $[6,7]$. The end products of their destruction are ordinary mammalian cell metabolites causing no toxic effect on the organism.

To reduce the risk of recurrent stenosis the following medicinal preparations are used: immunosupressors (sirolimus and its analogs), antitumor drugs (paclitaxel and its analogs) and so on [8].

The use of drug-eluting stents has been firmly implemented into practice of restoring vessel functions,

For contacts: Anastasiya D. Kruchinina, e-mail: a.d.kruchinina@mail.ru 
but only foreign items are widely presented in the market [9]. As import substitution in our country is a priority task, it is important to create similar products with the quality equal to that of the world leaders. In this connection, NanoMed company has developed sirolimus-eluting coronary stents with polylactid-co-glycolid as a polymer. The drug coating is applied on the stents above the layer of linear-chain carbon - an innovative material imparting the item a high biocompatibility and thromboresistance. Sirolimus release in the early terms after the operation will diminish excessive cell proliferation in response to the vessel wall traumatization, whereas availability of the inert coating from linear-chain carbon will reduce risks of restenosis and thrombosis at the later stages.

Creating a new medical product in Russia requires as an obligatory stage conducting investigations according to the state standard GOST R ISO 10993 "Medical products. Assessment of biological effect of medical products". Adherence to the issues of this standard series provides a systemic approach to the study of biological effect of medical products, since they are guiding documents for prediction and investigation at the stage of selecting materials for their fabrication, and at the stage of the finished products as well.

The aim of the investigation was to study the influence of sirolimus-eluting cardiovascular stents on hematological and biochemical blood parameters for the evaluation of the biological effect of these medical products on the animal organism in vitro.

Materials and Methods. The experiment was carried out on 12 male rabbits aged 8-10 months weighing $3.5-4.5 \mathrm{~kg}$. All stages of the work complied with GOST R ISO 10993. The animals were kept in compliance with GOST R ISO 10993-2-2011, were subject to quarantine and acclimatization in the vivarium for 14 days. The work was performed in accordance with ethical principles established by European Convention for the Protection of Vertebrata used for Experimental and other Scientific Purposes (the Convention was passed in Strasburg, March 18, 1986, adopted in Strasburg, June 15, 2006).

Experimental groups were formed by a simple fixed randomization by 6 animals in each. Prior to the operation blood was collected to define hematological and biochemical parameters which were used as the intact group values.

Angioplasty of aorta-iliac segment of the rabbit femoral artery was performed with implantation of MS $2.5 \times 11 \mathrm{~mm}$ bare Cobalt-Chromium stents and stents of the same model with linear-chain carbon and drug-eluting coatings ( $2 \mu \mathrm{g} / \mathrm{mm}^{2}$ of sirolimus) developed by NanoMed (Russia). The operation was performed by the specialists of the Federal Center of Cardiovascular Surgery of the Ministry of Health of the Russian Federation (Penza) in the Center of Preclinical Researches (Penza).

The control angiography after stent insertion showed that the artery at the sites of stent implantation was patent, the delivery system and guiding devices were removed, wounds were closed by layers.

Based on the time of coating resorption in vitro [10], the terms of biological material collection were established to study the effect of drug-eluting stents on hematological and biochemical blood indices: 1, 2, 4, 7 weeks following the implantation.

Blood was taken from the rabbit ear vein in the volume of $4-5 \mathrm{ml} ; 250 \mu \mathrm{m}$ were collected into microcuvettes with EDTA-K2 (Sarsted, Germany), hematological examinations were carried out using BC2800 Vet Auto Hematology Analyzer (Mindray, China). Sera were obtained by centrifuging blood during $15 \mathrm{~min}$ at 4,000 rpm in the OPN-8 laboratory centrifuge (AnalytNeva, Russia). Activity of enzymes and concentration of the substances recommended to be analyzed by GOST R ISO 10993-11-2011 (Appendix D.2) were determined in the obtained serum: alanine aminotransferase (ALAT), aspartate aminotransferase (ASAT), y-glutamyl transferase, alkaline phosphatase, albumin, glucose, calcium, creatinine, inorganic phosphorus, potassium, sodium, total and direct bilirubin, total protein, triglycerides, urea, chloride, total cholesterol.

Biochemical blood serum indices were determined by unified methods [11] using clinical kits (Olvex Diagnosticum, Russia). Optical specimen density was measured by means of KFK-3 photometer (Zagorsky Optico-Mechanical Plant, Russia) using cuvettes with $1 \mathrm{~cm}$ optical path length (Analyt-Neva, Russia).

To evaluate the experimental findings obtained, methods of statistical data processing have been used. The results were expressed in terms of arithmetic mean $(X)$ and standard deviation $( \pm S D)$. The hypothesis on the equality of the mean sampled values was verified using Student t-test. The delayed effect of specimen implantation was determined by means of variance analysis. Belonging of the animal subgroups to different homogenous groups was assessed with the help of Scheffe test.

Results and Discussion. Hematological investigation of the rabbit blood in the selected terms after stenting did not reveal any deviations of parameter values from those in the intact group, being the evidence of a good health condition of the animals after angioplasty. Findings of the analysis showed the absence of a marked inflammatory reaction in all terms following the operation and reactions of implant rejection in later terms (See the Table).

The analysis of the rabbit blood biochemical indices at all stages of investigation (Figures 1,2) showed the absence of systemic toxic influence of a new stent with the drug-eluting coating on the animal organism. In the early postoperative period, some changes in the biochemical parameters were observed, which are likely to be caused by the operative intervention. The values of biochemical blood indices after the implantation of sirolimus-eluting stents did not differ statistically significantly from those in the control animal group, 
Results of hematological investigations of the rabbit blood following the implantation of sirolimus-eluting stents $(n=6, X \pm S D)$

\begin{tabular}{|c|c|c|c|c|c|}
\hline Parameter & $\begin{array}{l}\text { Intact } \\
\text { animals }\end{array}$ & $\begin{array}{c}1 \text { week later } \\
\text { (experim./control) }\end{array}$ & $\begin{array}{c}2 \text { weeks later } \\
\text { (experim./control) }\end{array}$ & $\begin{array}{c}4 \text { weeks later } \\
\text { (experim./control) }\end{array}$ & $\begin{array}{c}7 \text { weeks later } \\
\text { (experim./control) }\end{array}$ \\
\hline Leucocytes (109/L) & $7.25 \pm 0.70$ & $9.96 \pm 0.40 / 10.12 \pm 0.50$ & $8.4 \pm 0.5 / 8.9 \pm 0.5$ & $7.80 \pm 0.42 / 8.24 \pm 0.40$ & $7.75 \pm 0.34 / 7.89 \pm 0.39$ \\
\hline Erythrocytes (1012/L) & $6.08 \pm 0.22$ & $6.70 \pm 0.48 / 6.76 \pm 0.43$ & $5.74 \pm 0.21 / 6.01 \pm 0.27$ & $5.77 \pm 0.25 / 5.94 \pm 0.20$ & $5.72 \pm 0.23 / 6.12 \pm 0.20$ \\
\hline Hemoglobin (g/L) & $131.17 \pm 7.52$ & $139.80 \pm 12.26 / 138.40 \pm 10.47$ & $125.33 \pm 6.11 / 127.80 \pm 7.21$ & $121.0 \pm 6.24 / 122.9 \pm 5.9$ & $126.0 \pm 3.84 / 122.0 \pm 3.51$ \\
\hline Hematocrit (\%) & $40.45 \pm 1.75$ & $42.84 \pm 3.44 / 40.67 \pm 2.50$ & $39.33 \pm 1.50 / 41.30 \pm 1.71$ & $39.8 \pm 2.1 / 39.5 \pm 3.1$ & $39.5 \pm 1.1 / 41.69 \pm 1.70$ \\
\hline $\begin{array}{l}\text { Mean corpuscular } \\
\text { volume (fl) }\end{array}$ & $66.50 \pm 2.04$ & $65.56 \pm 2.49 / 66.20 \pm 3.21$ & $68.70 \pm 5.02 / 69.10 \pm 4.98$ & $71.4 \pm 4.2 / 68.95 \pm 4.20$ & $70.6 \pm 3.3 / 69.4 \pm 2.5$ \\
\hline $\begin{array}{l}\text { Thrombocytes } \\
\left(10^{9} / \mathrm{L}\right)\end{array}$ & $373.0 \pm 125.59$ & $\begin{array}{c}358.20 \pm 45.57 / \\
358.7 \pm 44.1\end{array}$ & $\begin{array}{l}364.2 \pm 32.1 / \\
363.9 \pm 34.0\end{array}$ & $\begin{array}{c}346.33 \pm 56.04 / \\
347.11 \pm 55.20\end{array}$ & $\begin{array}{l}359.33 \pm 46.04 / \\
359.86 \pm 45.06\end{array}$ \\
\hline $\begin{array}{l}\text { Mean latelet } \\
\text { volume (fl) }\end{array}$ & $6.75 \pm 1.08$ & $7.2 \pm 0.9 / 7.4 \pm 0.8$ & $7.3 \pm 0.6 / 7.28 \pm 0.70$ & $6.83 \pm 2.74 / 6.89 \pm 2.60$ & $6.94 \pm 0.76 / 7.03 \pm 0.72$ \\
\hline Thrombocrit (\%) & $0.17 \pm 0.11$ & $0.19 \pm 0.06 / 0.20 \pm 0.05$ & $0.20 \pm 0.05 / 0.18 \pm 0.07$ & $0.24 \pm 0.03 / 0.26 \pm 0.02$ & $0.21 \pm 0.03 / 0.23 \pm 0.02$ \\
\hline Neutrophils (109/L) & $1.90 \pm 0.04$ & $3.10 \pm 0.04 / 3.20 \pm 0.03$ & $2.80 \pm 0.05 / 2.88 \pm 0.06$ & $2.30 \pm 0.07 / 2.50 \pm 0.06$ & $2.52 \pm 0.08 / 2.60 \pm 0.07$ \\
\hline Lymphocytes (109/L) & $4.12 \pm 0.06$ & $6.34 \pm 1.98 / 6.37 \pm 2.00$ & $6.60 \pm 1.78 / 6.78 \pm 1.54$ & $5.77 \pm 2.83 / 5.89 \pm 2.75$ & $6.67 \pm 1.82 / 6.70 \pm 1.91$ \\
\hline Monocytes (109/L) & $0.36 \pm 0.07$ & $0.36 \pm 0.09 / 0.39 \pm 1.00$ & $0.67 \pm 0.05 / 0.70 \pm 0.05$ & $0.30 \pm 0.17 / 0.36 \pm 0.18$ & $0.46 \pm 0.07 / 0.47 \pm 0.09$ \\
\hline Eosinophils (109/L) & $0.18 \pm 0.11$ & $0.10 \pm 0.05 / 0.10 \pm 0.06$ & $0.20 \pm 0.03 / 0.22 \pm 0.05$ & $0.20 \pm 0.02 / 0.23 \pm 0.02$ & $0.24 \pm 0.04 / 0.27 \pm 0.03$ \\
\hline Basophils $\left(10^{9} / \mathrm{L}\right)$ & $0.61 \pm 0.23$ & $0.70 \pm 0.11 / 0.78 \pm 0.10$ & $0.65 \pm 0.01 / 0.70 \pm 0.02$ & $0.68 \pm 0.08 / 0.70 \pm 0.06$ & $0.72 \pm 0.07 / 0.75 \pm 0.08$ \\
\hline Granulocytes (109/L) & $4.20 \pm 0.65$ & $5.60 \pm 1.28 / 5.63 \pm 1.32$ & $6.23 \pm 1.27 / 6.27 \pm 1.50$ & $3.73 \pm 0.91 / 3.75 \pm 0.90$ & $5.53 \pm 0.61 / 5.61 \pm 0.80$ \\
\hline
\end{tabular}

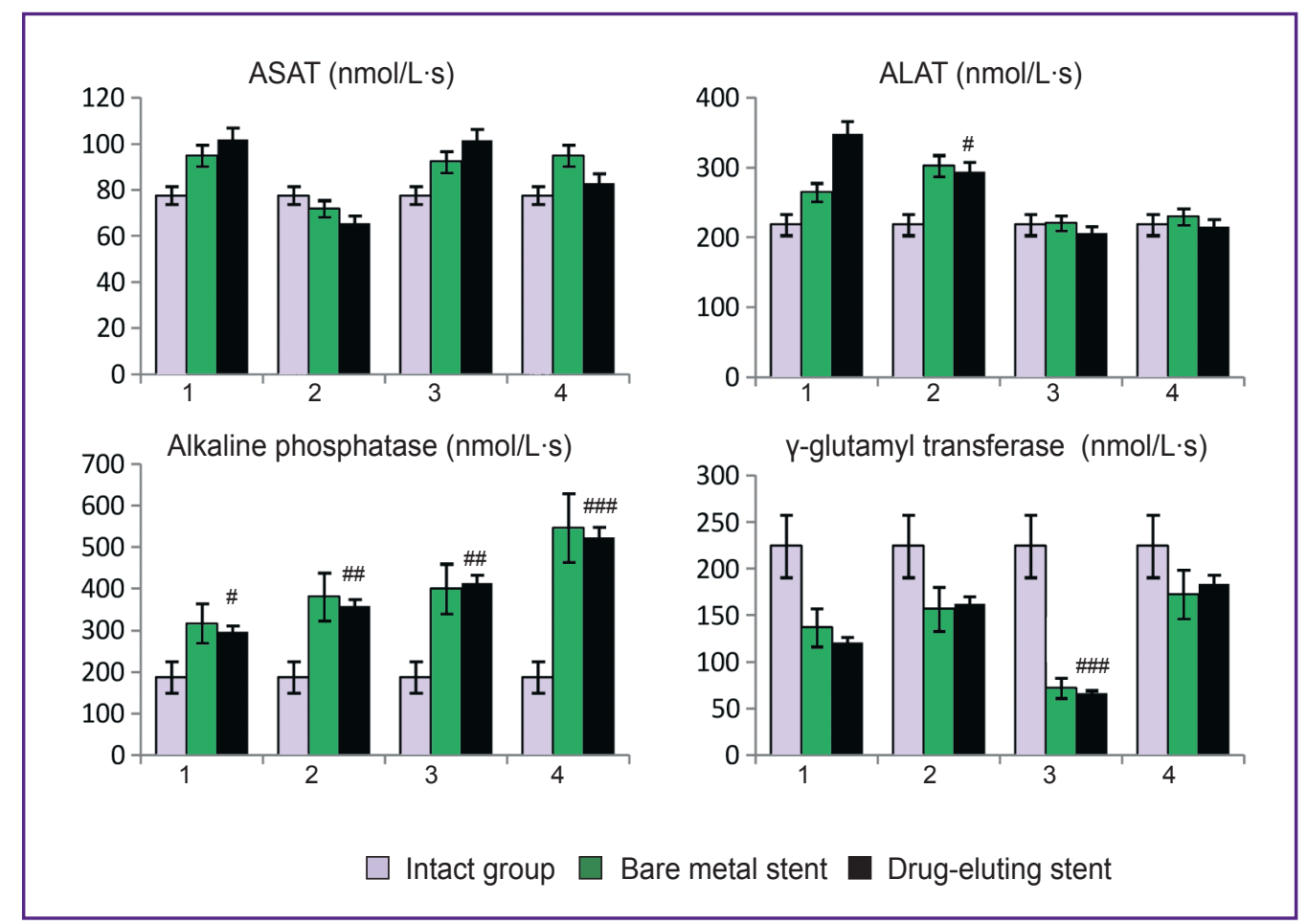

Figure 1. Activity of enzymes and concentration of albumin, glucose, total cholesterol, triglycerides in the rabbit blood serum in different terms following stenting ( $n=6, X \pm S D)$ : (1) 1 week; (2) 2 weeks; (3) 4 weeks; (4) 7 weeks; statistically significant values compared to the intact group: \# $p<0.05$; $\#$ p $<0.01$; ${ }^{\#} p<0.001$; in comparison with the control group: * $p<0.05$ (See Figure 1 continued) 


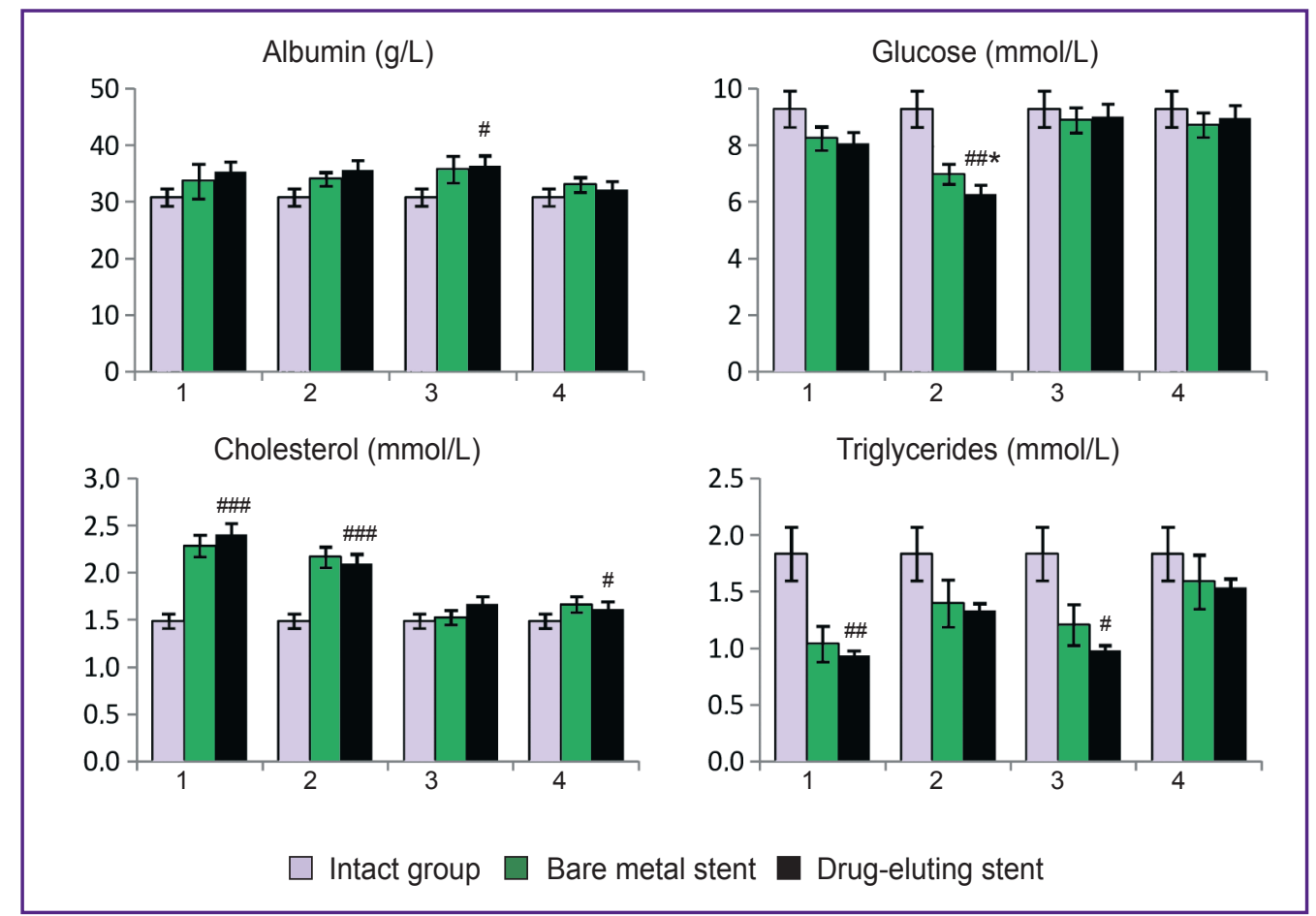

Figure 1 continued

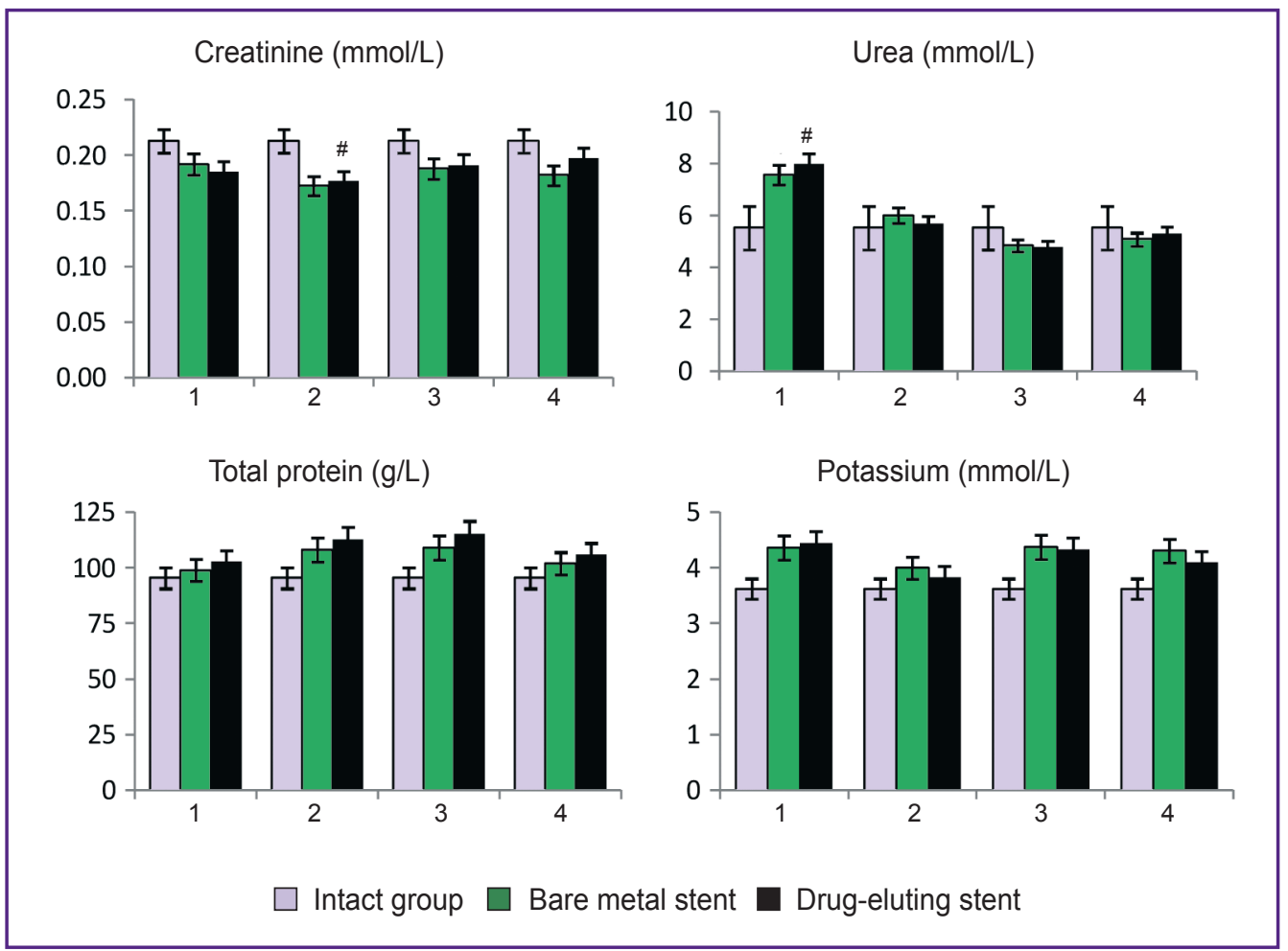

Figure 2. Concentration of creatinine, urea, total protein, ions of potassium, calcium, sodium, phosphates and chlorides in different terms following stenting $(n=6, X \pm S D)$ : (1) 1 week; (2) 2 weeks; (3) 4 weeks; (4) 7 weeks; statistically significant values compared to the intact group: \# $p<0.05 ; \# p<0.01$ (See Figure 2 continued) 


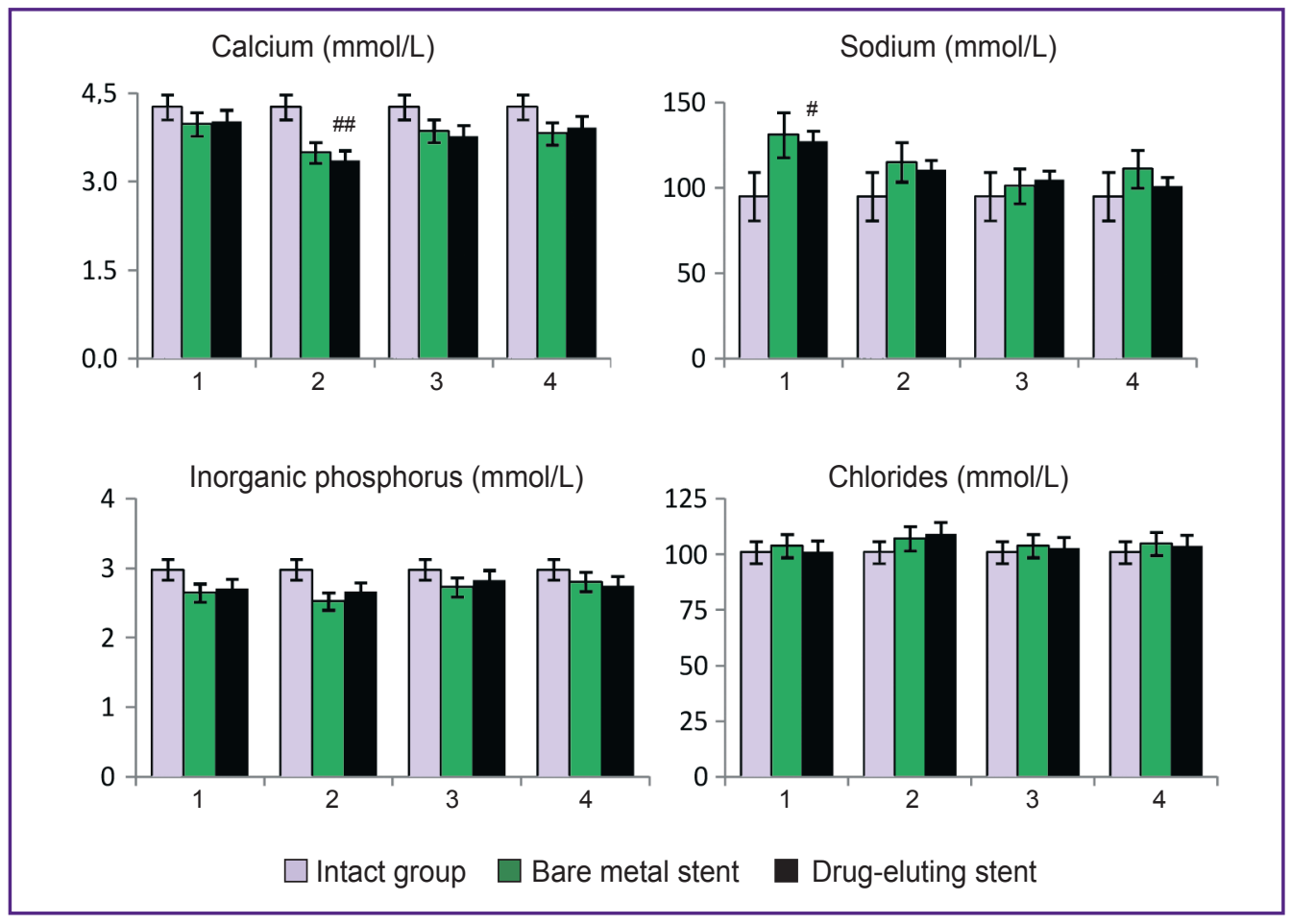

Figure 2 continued

which underwent angioplasty using bare metal CobaltChromium stents.

The data obtained also testify to the positive dynamics of restoration, and absence of the delayed negative reaction to the implant on the part of the animal organism.

Conclusion. The results of the conducted experimental study have demonstrated the absence of toxic effect of the developed medical product on the animal organism, which confirms the compliance of the stents with linear-chain carbon plus drug-eluting coatings, developed by NanoMed, with the biological safety and toxicity requirements applied to medical products.

Study Funding and Conflicts of Interest. The work was not supported by any source. There are no conflicts of interest related to this study.

\section{References}

1. Karpov Yu.A., Samko A.N. Buza V.V. Koronarnaya angioplastika i stentirovanie [Coronary angioplasty and stenting]. Moscow: MIA; 2010.

2. Fedorchenko A.N. Restenoz kak osnovnaya problema posle chreskozhnykh koronarnykh vmeshatel'stv. Avtoref. dis. ... dokt. med. nauk [Restenosis as the main problem following percutaneous coronary interventions. DSC Thesis]. Novosibirsk; 2009.

3. Bokeriya L.A., Alekyan B.G., Golukhova E.Z., Buziashvili Yu.I., Nikitina T.G. Staferov A.V., Zakaryan N.V. Application of stents with antiproliferative drug-eluting coatings in managing patients with ischemic heart disease. Kreativnaya kardiologiya 2007; 1-2: 183-199.

4. Bokeriya L.A., Alekyan B.G., Zakaryan N.V., Staferov A.V. Koronarnoe stentirovanie: sovremennoe sostoyanie voprosa. V kn.: Rukovodstvo po rentgenoendovaskulyarnoy khirurgii serdtsa $i$ sosudov. T. 3 [Coronary stents: current status. In: Texbook of endovascular surgery for cardiovascular diseases]. Pod red. Bokeriya L.A., Alekyana B.G., Anri M. [Bokeriya L.A., Alekyan B.G., Anri M. (editors)]. Moscow; 2008; p. 232-260.

5. Li Ch.Kh., Serruyz P.U. Stents with drug-eluting coatings. Mezhdunarodnyy zhurnal interventsionnoy kardioangiologii 2003; 1: 9-18.

6. Adamyan A.A. Main directions and perspectives in creation and clinical application of polymer implants. Biosovmestimost' 1994; 2: 97-107.

7. Sevast'yanov V.I., Kirpichnikov M.P. Biosovmestimye materialy [Biocompatible materials]. Moscow: MIA; 2011; $544 \mathrm{p}$.

8. Yin R.-X., Yang D.-Z., Wu J.-Z. Nanoparticle drugand gene-eluting stents for the prevention and treatment of coronary restenosis. Theranostics 2014; 4(2): 175-200, https:// doi.org/10.7150/thno.7210.

9. Ielasi A., Latib A., Colombo A. Current and future drugeluting coronary stent technology. Expert Rev Cardiovasc Ther 2011; 9(4): 485-503, https://doi.org/10.1586/erc.11.5.

10. Lyubchenko O.D., Kruchinina A.D., Shatrov A.N. Kinetics of degradation of antiproliferative polymer coating of stents in vitro. Izvestiya vysshikh uchebnykh zavedeniy. Povolzhskiy region. Estestvennye nauki 2015; 2(10): 55-61.

11. McPherson R.A., Pincus M.R. Henry's clinical diagnosis and management by laboratory methods: 22nd edition. Elsevier Saunders, Philadelphia; 2011. 